\title{
A cola "assistida" e aprendizagem decorrente: um estudo nas provas escritas de análise de investimentos
}

\author{
Francisco Isidro Pereira - fisidro30@ hotmail.com \\ Universidade Federal do Ceará
}

\begin{abstract}
Resumo
Há um pressuposto que arremata a ideia de que da cola praticada por alunos durante a feitura de sua avaliação escrita emerge a aprendizagem desejada. Será? Ser complacente com uma atitude pouco nobre, como a "pesca", no ato de mensurar o que se aprendeu ajuda a consolidar a aprendizagem requerida? Com intuito de esclarecer a questão este estudo partiu de um estudo de caso o qual o próprio investigador fez parte do setting de pesquisa. Foram consideradas duas turmas no percurso dos semestres de 2012, 2013 e 2014. A captura dos dados se deu parte da aplicação de quatro provas, as quais distribuídas equitativamente nos semestres respectivos e essencialmente via a observação. O professor permitiu, ainda que informalmente, a cola, disfarçando seu desinteresse. O registro da captura de dados foi feito por meio de documentos no formato de provas e anotações circunscritas no diário de campo. O plano analítico foi concretizado por meio de contrastes teóricos e reflexões oriundas dos dados condensados. Os resultados se mostraram um tanto imprecisos haja vista que a maioria dos alunos não obteve o êxito do tamanho esforço despendido na consulta não autorizada. Por outro lado, foram constatados desempenhos de aprendizagem mesmo com ajuda entre eles.
\end{abstract}

Palavras chave: Cola, aprendizagem, prova escrita.

\begin{abstract}
There is a presumption that concludes the idea that the cheating practiced by students during the making of their written evaluation emerges the desired learning. It will be? Be complacent with a little noble attitude, like the practice of cheating in the act of measuring what has been learned helps consolidate learning required? In order to clarify the question this study was based on a case study in which the investigator himself was part of the setting of the research. Two classes were considered in the course of semesters of 2012 and 2013. Capture of data was part of the implementation of four trials, which evenly distributed in the respective semesters and essentially via observation. The professor agreed, albeit informally, act of cheating on exams, masking his disinterest. The registry data capture was done by means of documents in evidence and diary entries circumscribed field format. The analytical plan was achieved through theoretical contrasts and reflections derived from the combined data. The results were somewhat inaccurate considering that most students did not achieve the success of the effort expended in unauthorized viewing size. Moreover learning performances even with assistance between them were founded.
\end{abstract}

Key words: cheating on exams, learning, written test. 


\section{Introdução}

Conduzir uma miscelânea de atividades no habitat da sala de aula chega a se tornar um trabalho hercúleo no âmbito universitário. Não obstante, na busca de uma real aprendizagem todos os meios valem a pena ser tentados, minando assim a subjetividade em grau elevado de sua avaliação.

É claro que o cotidiano da paisagem universitária não conduz com o teor da afirmativa anterior. A realidade empírica vivenciada pelo autor assinala fortemente que as pressões em torno de edificações bibliográficas reduzem sensivelmente no pensar em instrumentos de objetos de avaliação. A própria implementação de um projeto de pesquisa demanda um tempo aquém do programado requerendo do professor em sala de aula de recorrer ao artefato de avaliação mais usual e de fácil aplicação nas disciplinas de natureza quantitativa: a prova escrita.

Não se debruçará sobre os aspectos positivos e/ou negativos, os quais amplamente disponíveis no formato de discussões na literatura, mas partirá da existência de um pressuposto que arremata a ideia de que a "cola" praticada por alunos durante a feitura de sua prova escrita emerge a aprendizagem desejada.

Ao reunir opiniões de especialistas educadores que sustentam o afloramento da aprendizagem em qualquer situação, a cola não seria de todo um mal, muito menos uma desonestidade praticada pelo aluno.

A conexão da busca da resposta de uma questão atrelada ao objeto de consulta não permitido reteria o conhecimento desejado e consequentemente provocaria a aprendizagem almejada.

Assim, ser complacente com uma atitude pouco nobre, como a "cola", no ato de mensurar o que se aprendeu, ajuda a consolidar a aprendizagem requerida? Delinear uma resposta para essa inquietação foi o intento da construção do texto em tela. Assim o objetivo do estudo foi mensurar a aprendizagem decorrente de uma "cola".

O burburinho e o frison durante a aplicação de uma prova se constituíram na base epistemológica da investigação.

A relevância do estudo remete a Barbosa (2013) segundo o qual a "cola" raramente é abordada no interior das instituições de ensino superior e quando se comenta é de forma jocosa, imatura e sem importância. A "cola" existe, mas não é discutida. Soma-se a isso, o fato de não ter detectado até a redação final deste texto, nenhum estudo de natureza empírica do objeto de pesquisa.

Juntamente com esta introdução, o artigo em apreço está pautado em cinco seções, a saber: a seção 2 remonta o aparato teórico para servir de sustentação o teor da seção final, que trata das considerações finais onde concilia o corpo teórico e os achados empíricos, os quais objetos da seção 4 . A seção 3 descreve o procedimento metodológico.

\section{$O$ contexto atual da sala de aula}

Wood Jr. (2013) se reporta ao quadro pintado por Laurentis de Voltolina no século XIV para comparar uma aula daquele período com a dos tempos de hoje. "Do lado esquerdo, sentado em um púlpito elevado, vê-se o pomposo professor. À sua frente e à sua lateral, em fileiras de carteiras fixas, encontram-se pouco mais de 20 estudantes. Apenas quatro ou cinco deles parecem escutar atentamente o mestre, alguns miram seus cadernos, outros conversam e dois parecem dormitar."

Séculos depois, a cena das salas de aula não parece ter mudado. $O$ visitante que entrar hoje, ao acaso, em uma sala de aula, vai provavelmente se deparar com cena similar. O mestre talvez seja mais jovem e o comunicativo do que aquele da pintura de Voltolina. Entretanto, à sua frente estarão os mesmos estudantes entediados. Poucos estarão atentos à cena, muitos outros estarão mergulhados em notebooks e smartphones, alguns, provavelmente, estão cochilando.

Consoante o autor a escola permanece, para muitos, um lugar de enfado e tédio, ou sacrifício a fazer por um diploma. Séculos preservaram a essência da instituição. Décadas 


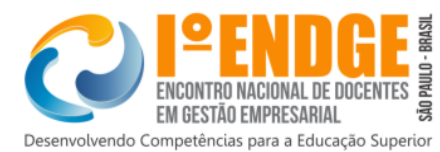

recentes de desenvolvimento pedagógico não lhe alteraram as feições e os últimos anos de revolução tecnológica parecem ainda não ter surtido efeito. $\mathrm{O}$ quadro negro deu lugar à tela. $\mathrm{O}$ computador substituiu o giz. Agora a "febre" são as aulas em vídeo no YouTube. No entanto, registra o autor, são as mesmas aulas de sempre, ou versões pioradas.

Conforme Demo (2005) discutir aprendizagem torna-se procedimento estratégico. O pensamento não é apenas material, sequencial, digital, algorítmico, mas altamente significativo, subjetivamente irrepetível e insubstituível, naturalmente criativo e intrinsecamente autônomo. Aprendizagem é dinâmica, tipicamente reconstrutiva, feita de dentro para fora. Sob essa lógica conhecer não é confirmar, afirmar, verificar, constatar, mas questionar. Ela não se repassa, não se transmite, não se reproduz, mas se constrói. Na dinâmica do conhecimento existe sempre a atividade desconstrutiva, de um lado, e, reconstrutiva, de outro, agindo de maneira recíproca e contrária, ao mesmo tempo, de dentro para fora.

Remetendo a Lowman (2004) para a maior parte dos estudantes e para muitos professores universitários, os testes e as notas são uma realidade desagradável, mas inevitável. Todos os estudantes são preocupados com exames e notas, assinala Lowman (2004). Os estudantes dependentes-ansiosos ou fracos receiam-nos, e qualquer estudante pode tornar-se desnecessariamente orientado para as notas. Em contraste, o aluno mais independente, capaz e orientado para a aprendizagem, anseia pelo desafio e sucesso potencial que os exames oferecem. Para a maioria dos estudantes, o fato de ser avaliado provoca uma mistura de ansiedade e antecipação positiva.

A despeito das recentes discussões tecidas, exames e outras atividades introduzem a possibilidade de colar, o que induz à culpa os que sucumbem à tentação, à raiva os colegas que observam ou descobrem a infração e ao desprazer o professor que toma conhecimento (LOWMAN, 2004).

Embora a cola entre os estudantes universitários não possa ser justificada ou perdoada, as motivações que levam a ela são universais e compreensíveis demais para permitir tratar impiedosamente os coladores (LOWMAN, 2004 e GIL, 2006). Um professor não deve olhar a cola apenas em termos de certo ou errado, honroso ou desonroso. A maioria dos alunos é capaz de colar, desde que lhe sejam dadas as razões e oportunidades suficientes. Mesmo alunos que não necessitam colar para serem aprovados podem ser tentados a fazer uso da cola em virtude de fortes pressões para obter notas mais altas. Também há alunos que colam alegando que outros também colam, e como os professores não os pegam, não haveria por que não colar (GIL, 2006).

Conforme Santos (2014) a cola tanto aumenta quanto maior é o descrédito do aluno pela prova. A cola justamente contesta o sistema de avaliação de provas. Estas mensuram as capacidades individuais do aluno entregue aos seus próprios conhecimentos. A cola perverte essa avaliação, suprindo o aluno por outras fontes.

\section{Cola: uma fraude escolar ou uma oportunidade de aprendizagem?}

Como analisa Pimenta (2010) a avaliação é uma prática relevante para o ser humano, pois é ela que, em geral, subsidia a tomada de decisões pessoais e profissionais. Fato é que as pessoas estão constantemente avaliando e sendo avaliadas. Na educação, a avaliação compreende uma dimensão fundamental do processo ensino-aprendizagem. É ela que permite identificar se a aprendizagem está acontecendo, ou não, e o que precisaria ser alterado na prática pedagógica visando à melhoria e à qualidade do ensino. Mas o que fazer quando a mesma é fraudada? Ou seja, quando o estudante simula - por meios de recursos ilegítimos - que detêm um conhecimento que não possui, de fato, ou que aprendeu algo que não aprendeu.

Nessa perspectiva conceitual de transgressão, de equívoco e de ilegalidade há também uma glamorização. Esta é promovida por parte de alguns estudantes e, principalmente, quando ela é considerada inócua, como parece ser o caso da praticada nas escolas - uma vez que há tolerância e não enfrentamento.

Evidência inclusive apontada por Ioschpe (2014) segundo o qual tal leniência tem pelo menos duas consequências: $1^{\circ}$ ) ela deslegitima todo o discurso da escola sobre "formar cidadãos 


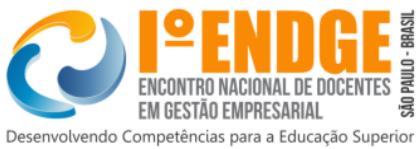

críticos e conscientes", sobre ser o lugar onde as crianças aprendem "valores". Ora, se o discurso é diferente da prática - se aqueles que praguejam contra as altas autoridades da nação agem como eles, tolerando a pequena corrupção em troca de suposta harmonia no convívio -, então é óbvio que toda a peroração será vista como hipocrisia e descartada. Crianças e jovens tem faro aguçado para demagogos; $2^{\circ}$ ) a escola injusta e antiética é a incubadora da sociedade injusta e antiética. A escola, pelo poder que tem e pelo tempo que fica com os alunos em fase de formação, precisa ser um fator dissuasivo. Em vez disso, ao tolerar cola, ela apenas coloca mais "lenha na fogueira" da iniquidade. Em países onde há mais cola na escola, há mais desonestidade na vida adulta, e aqueles que mais colam são também os mesmos que, quando adultos, mais mentem para seus clientes, exageram despesas para seus empregadores e trapaceiam suas seguradoras. Alcançar um nível de honestidade se tora difícil enquanto existirem escolas, que são verdadeiros teatros, em que as crianças crescem acreditando que trabalho duro, dedicação e seriedade são coisas de otário, instiga o autor.

Com esse entendimento, Barbosa (2013) enfatiza que as discussões sobre a prática da cola devam ser constantes, não com o objetivo de agredir os adeptos, mas na expectativa de fazê-los perceber que tipo de construção de si mesmos se condicionaram e se viciaram a estabelecer com a sociedade onde vivem e realizam suas práticas sociais. No futuro próximo provavelmente um profissional não praticante da "cola" quando estudante, não convidará um daqueles alunos que "colaram" na faculdade, para juntos, estabelecerem uma sociedade de negócios, ou mesmo para participarem de um mesmo grupo de trabalho específico. Uma vez desonesto e sem ética, ao praticar "cola", será difícil confiar em tal pessoa em outra situação.

A cola na escola é uma espécie de prática institucionalizada. Isso é corroborado por Ioschpe (2014) ao afirmar que a cola é um fenômeno entranhado nas instituições de ensino brasileiras e se sustenta em dados de pesquisa. Insiste Santos (2014) que a cola é uma daquelas práticas amplamente disseminadas, mas cuja importância é esquecida e não levada em conta.

Argumento inusitado como o que foi apresentado ao pesquisador, por alunos momentos antes de realizar uma prova, de uma docente cujo histórico de vida universitária havia sido marcada por colas e que tal rumor havia sido disseminado entre o corpo discente, mostra o quanto fortalece a afirmativa anteriormente exposta.

Para Ioschpe (2014) a cola aqui e acolá é socialmente aceita. Só se pode colar tanto quando alguém faz vista grossa. Esse alguém é o professor. Quem quer que já tenha olhado, de pé, uma turma de alunos sentados, em silêncio, fazendo uma prova, sabe que é praticamente impossível não notar a cola acontecendo.

Conforme Barbosa (2013) para os que praticam e incentivam a "cola", qualquer esforço rumo ao conhecimento é algo radical: as avaliações que requerem leituras anteriores e interpretação, os professores que contextualizam as suas aulas, o colega que compra livros, os colegas que acessam a internet para realizar pesquisas e não praticam o Control C, Control V, irresponsavelmente; os professores que indicam leituras para a discussão de temas em sala de aula para citar os principais. Para os que "colam" tudo isso é invenção, a fim de complicar o prosseguimento de mais um período de um curso superior. Quando esses alunos vão à biblioteca da instituição, o objetivo é a construção das estratégias de "colas", a partir das cópias daquilo que julgam quase certo constar na próxima avaliação. Nos dias das avaliações, esses alunos ocupam os assentos de forma estratégica em sala de aula. Há todo um cenário, criminosamente construído na maioria das vezes. Entre os alunos que ocupam esses assentos, estão também os que costumam faltar às aulas diárias ou chegam sempre atrasados, nesses dias de avaliações eles são escandalosamente assíduos e pontuais; chegam antes do professor ou da professora e sentam-se ardilosamente preparados para violentaram a própria consciência. Estão prontos para mais um exercício da "cola".

Dando sequencias às descrições supra, vale ampliá-las pelas próprias observações informais do pesquisador, no tocante de em vez de o aluno se posicionar em lugares estratégicos da sala decidem todos ficarem bem próximos, facilitando assim, sem a menor cerimônia, o troca-troca de informações, o ti-ti-ti de discussões rasteiras da questão. E aqui acontece o que Barbosa (2013) assinala de professores acreditarem que exista uma série de dificuldade de 
compreensão de leituras, por parte daqueles que "colam", haja vista não serem, poucas as vezes que, mesmo "colando", as suas respostas não têm senso - supondo inclusive fortes dificuldades em interpretar as perguntas.

Mas afinal, quem cola aprende alguma coisa? Para os especialistas, o aluno aprende através de relações que estabelece a partir daquilo que o professor traz, como atividades, textos, informações. O aluno vai se apropriando e tornando isso conhecimento. A prova, ou outro instrumento de avaliação, vai ajudar a perceber onde ficaram as dificuldades ou não.

$\mathrm{Na}$ visão de Ribeiro (2004) a cola é resultado de uma aprendizagem não significativa. O aluno não cola aquilo que entende. Se o professor avalia continuamente, passando tarefas menores, gradativas e sequenciais, pode-se verificar com clareza a aprendizagem do aluno em vários momentos de forma complementar.

Mas mesmos professores que procuram diversificar os instrumentos de avaliação podem deparar com a cola na classe. Dentro dos padrões vigentes, a cola é um ato desonesto, assim como a mentira. Mas quebrar regras nem sempre é sinônimo de falta de ética. Consultar anotações na hora da prova não é motivo para criar um bicho-de-sete-cabeças. A cola é uma situação potencialmente educadora (RIBEIRO, 2004).

Não se pode confundir aqui a prova com consulta. Esta é, aliás, considerada um melhor antídoto da cola. Ela tem como objetivo estimular a capacidade de argumentação. Durante os testes, os alunos podem consultar cadernos, livros, textos e até uns aos outros, desde que não copiem.

Finalmente cabe resgatar Khan (2013) ao provocar no que as provas realmente provam. Para ele o máximo que se pode dizer com confiança que tais instrumentos medem é o estado aproximado da memória de um aluno e talvez sua compreensão sobre um subtópico específico da matéria num dado momento, entendendo-se que a medição pode variar consideravelmente e aleatoriamente, de acordo com as perguntas formuladas (grifo original). Deixa claro, todavia, que não é contra provas e quaisquer tipos de exames. Eles podem ser valiosas ferramentas de diagnóstico para identificar lacunas que precisam ser reparadas na aprendizagem. Provas bem planejadas, também podem ser usadas como evidência de que alguém efetivamente conhece bem um tópico de uma matéria num determinado momento. É importante lembrar, na sua percepção, de ter uma dose sólida de ceticismo ao interpretar resultados, mesmo para as provas planejadas com o máximo de cuidado, pois afinal de contas, são meras criações humanas imperfeitas.

\section{Delineamento metodológico adotado}

A definição de "cola" para os propósitos da reflexão aqui edificada se refere a atitude dos alunos em responder às perguntas de uma avaliação, uma prova, um exame ou um teste, a partir das informações obtidas de um colega ou de uma colega, ou anotadas num papel, no telefone celular, atrás das cadeiras ou no próprio corpo.

Foi considerada a definição de avaliar conforme a perfilada por Barbosa (2013) a qual se refere a atribuir qualidade a alguma coisa, e relacionar as expectativas da disciplina em estudo com a aprendizagem do aluno, é compreender como os atos cognitivos têm se tornado em atos reais. A Figura 1 esclarece esquematicamente no que consiste o domínio cognitivo.

O setting de pesquisa foi a sala de aula, por ocasião do encontro entre o pesquisador, que simultaneamente atuou como professor e aluno. Estes, portanto, se constituíram nos sujeitos da pesquisa. $\mathrm{O}$ sujeito pode ser definido como uma pessoa, portadora de uma fala concreta, regida pelas qualidades pré-conscientes de toda fala (ELIA, 2010) e devidamente matriculado na disciplina Análise de Investimentos da Universidade Federal do Ceará, de duas turmas, nos semestres 2012.1, 2012.2, 2013.1 e 2013.2, períodos, inclusive, coberto pela pesquisa.

Urge esclarecer que o termo cola "assistida" se deve ao fato do professor-pesquisador permitir, ainda que informalmente, a pesca, como também é conhecida em linguagem regional, disfarçando seu desinteresse. 
Durante a aplicação da prova somente os alunos que recorreram ao recurso da "cola" foram considerados como amostra da pesquisa. Após a conclusão da mesma tal artefato era codificado. Foram quatro provas, as quais aplicadas equitativamente nos semestres respectivos.



Figura 1 -Elementos constituintes do domínio cognitivo

Fonte: Elaborado pelo autor

Para se mensurar a aprendizagem foi adotada uma escala de zero a dez, tendo como critério de aferição uma nota acima de cinco, a qual apurada conforme os valores distribuídos nas dez questões afixadas na prova. Em verdade levou-se em conta um acerto percentual de $51 \%$ do total de dez pontos.

A aprendizagem era confirmada e, portanto, o valor da questão pontuada em $100 \%$ se o aluno procedesse: a) interpretação, b) fizesse conexões e c) tecesse comentários com as próprias palavras. A pontuação poderia variar dependendo da ausência de uma das variáveis recém elencadas. Ou seja, as variáveis não se qualificavam como mutuamente excludentes. A identificação de tais variáveis remete a Moretto (2008) ao relacionar a interiorização da informação a um significado dentro do contexto das experiências pessoais e do contexto social em que se vive para assim aflorar o conhecimento.

Na configuração da cola bem como a mensuração da aprendizagem decorrente o método de captura selecionado foi a essencialmente a observação. Esta se qualifica como investigação científica quando é conduzida especificamente para responder a uma questão de pesquisa (COOPER e SCHINDLER, 2003) e esta se perfilou essencial na implementação da pesquisa que ora se encontra relatada neste documento.

A observação inclui todo o âmbito de atividades e condições de monitoramento comportamental e não comportamental.

Para proceder o estudo observacional comportamental dos alunos em processo de "cola", foi considerado 3 categorias:

1. comportamento não-verbal que inclui o movimento do corpo, expressões motores e até olhares trocados;

2. comportamento linguístico que envolve os processos de interação que ocorrem entre duas pessoas ou em grupos pequenos; e

3. comportamento que abarca as relações espaciais, pela qual as pessoas organizam o território ao seu redor e como mantêm distâncias discretas entre elas próprias e as outras pessoas.

Dentre a observação não comportamental sobressaiu a análise de registro a qual envolveu os escritos das respostas das questões constituídas na Avaliação Parcial 1 (AP1) e Avaliação Parcial 2 (AP2) e quizzes.

Há ainda que considerar que o estudo de observação procedido foi do tipo naturalista, já que esta se deu em ambiente real, sem que houvesse a intervenção do observador no fluxo de acontecimentos, interações e comportamentos naturalmente emitidos pelos indivíduos (MOURA, FERREIRA e PAINE, 1998). 
Becker (1999) instiga qual a credibilidade das conclusões derivadas de dados coletados pelo trabalho de campo.

Para contrastar os dados recolhidos e validar a aprendizagem com a cola foram aplicados quizzes indistintamente contendo as mesmas questões das provas, porém codificando aqueles de alunos que obtiveram nota superior a cinco.

$\mathrm{O}$ registro da captura de dados foi feito por meio de documentos no formato de provas e anotações circunscritas no diário de campo. Sobre o diário de campo o pesquisador se debruça no intuito de construir detalhes que no seu somatório vai congregar os diferentes momentos da pesquisa. Demanda um uso sistemático que se estende desde o primeiro momento da ida ao campo até a fase final da investigação. Quanto mais rico for em anotações esse diário, maior é o auxílio que oferece à descrição e à análise do objeto estudado (CRUZ NETO, 1994).

O plano analítico foi concretizado por meio de contrastes teóricos e reflexões oriundas dos dados condensados.

Finalmente a pesquisa se configura como estudo de caso dada a particularidade envolvida que focaliza uma situação, um fenômeno particular (ANDRÉ, 2005). Mais particularmente trata-se de um estudo de caso educacional, em consonância a definição de Stenhouse (1988) em que se busca a compreensão da ação educativa. Aqui os pesquisadores buscam enriquecer o pensamento e o discurso dos educadores seja pelo desenvolvimento de teoria educacional, seja pela documentação sistemática e reflexiva de evidências.

\section{Análise dos Resultados}

No cenário de coleta dos dados, os sujeitos que foram submetidos a "cola" assistida, tinham ciência da flexibilidade do professor quanto o rigor na condução da aplicação da prova, sendo esse inclusive reforçado por parte do mesmo, ainda que tenha insistido na honestidade por ocasião da feitura das referidas provas.

Não obstante, em nenhum momento, se obteve a unanimidade da concentração individual de cada turma. Sempre um cochicho, uma "olhada" para ambos os lados, quando muito uma virada sem o menor constrangimento da presença do professor. Tais ações são compartilhadas com o uso do aparelho celular. O aplicativo whatsapp foi fortemente acionado. Não só para confirmar respostas como a busca da mesma. $\mathrm{O}$ acesso ao site de busca se perfilou sensivelmente demandado inclusive servindo como referência para colegas.

Foi constatado ainda o recurso da fotografia de questões e seu envio via e-mail não só no próprio ambiente de investigação como externamente.

O material de estudo tais como anotações avulsas, caderno, textos, exercícios resolvidos, slides impressos, não é de todo isento do contexto. Acondicionados no chão, ao lado ou mesmo na frente da carteira se constituem em mais um recurso de consulta não permitido.

Ao longo do período de investigação, ainda que não usual, foi observado a escrita circulando entre os indivíduos. Em formato de diálogo os alunos procuravam dirimir dúvidas e checar o grau de resposta alcançada do colega como demonstra a Figura 2.

Todas as questões foram elaboradas de forma a captar do aprendiz o que foi retido emergindo-o a uma situação recortada da realidade. Esta contém detalhes que estão inerentes ao teor do material de estudo cuja dedução decorresse da reflexão e o entendimento no processo cognitivo enquanto se procedia a leitura sem que recorresse à "cola". Do contrário, essa reflexão se manifestaria? O Quadro 1 exibe uma resposta um tanto imprecisa. 


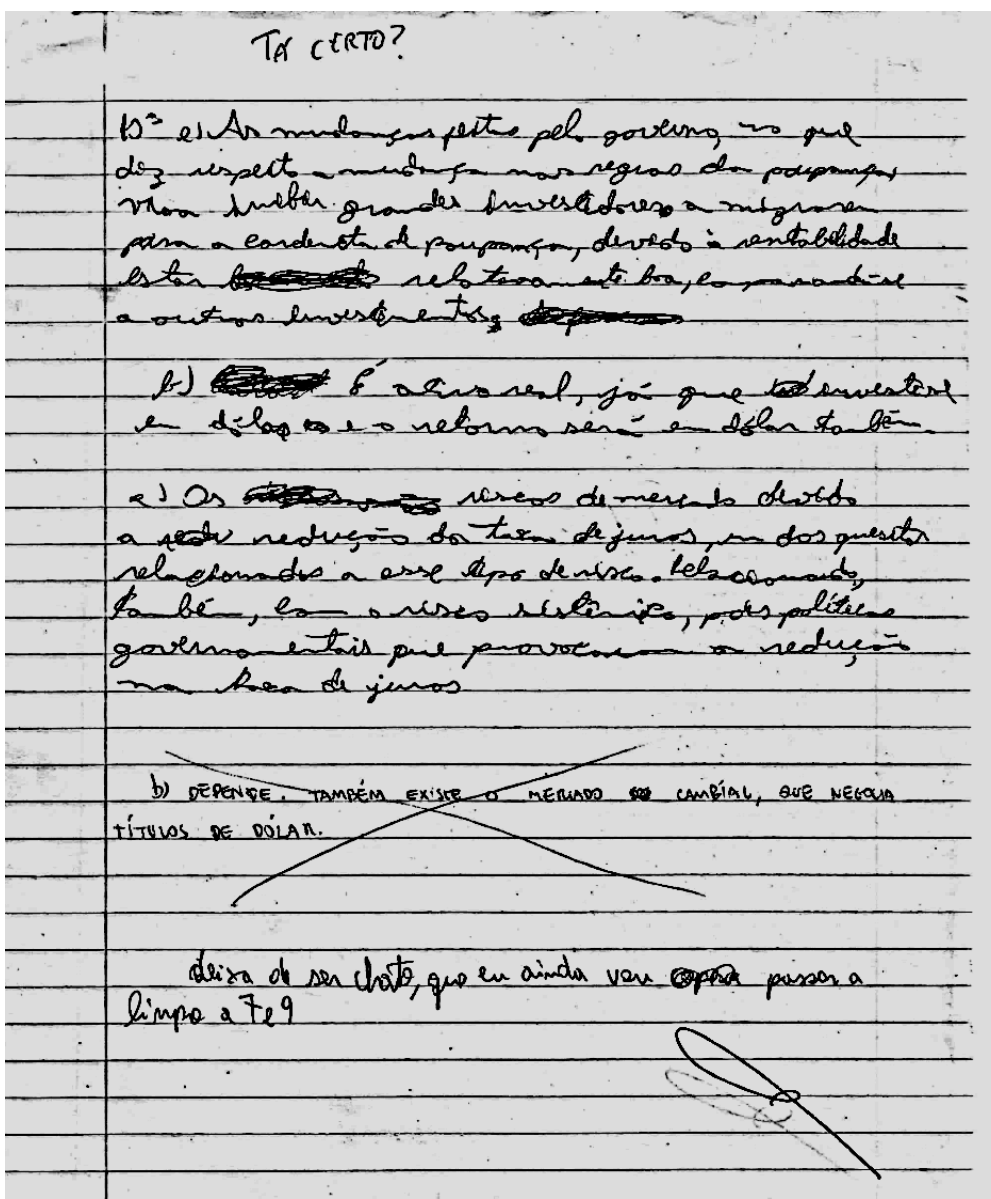

Figura 2 - Objeto de "cola" capturada no ambiente de pesquisa

Fonte: Pesquisa de campo

Quadro 1 -Média percentual de discentes que obtiveram rendimentos acima de 5 com a "cola" assistida

\begin{tabular}{|c|c|c|c|}
\hline \multirow[t]{2}{*}{ Semestres } & \multirow[t]{2}{*}{$\mathbf{A P}$} & \multicolumn{2}{|c|}{ Turmas } \\
\hline & & 1 & 2 \\
\hline \multirow[t]{2}{*}{2012.1} & 1 & 10,0 & - \\
\hline & 2 & 15,0 & - \\
\hline \multirow[t]{2}{*}{2012.2} & 1 & 21,4 & - \\
\hline & 2 & 7,1 & - \\
\hline \multirow[t]{2}{*}{2013.1} & 1 & 18,9 & 22,7 \\
\hline & 2 & 25,0 & 13,6 \\
\hline \multirow[t]{2}{*}{2013.2} & 1 & 27,3 & 23,8 \\
\hline & 2 & 18,2 & 19,1 \\
\hline 2014.1 & 1 & 15,4 & 9,3 \\
\hline \multicolumn{2}{|c|}{ Média } & 33,2 & 30,3 \\
\hline
\end{tabular}

Fonte: Pesquisa de campo

Já excluídos aqueles alunos que usualmente se posicionam para proceder a prova de forma isolado e sem a interferência de qualquer colega e/ou objeto de consulta a média semestral por turma foi respectivamente de $33,2 \%$ e $30,3 \%$ com rendimento acima de cinco o que não se mostra desprezível. De alguma forma a aprendizagem foi manifestada, pois ao contrastar tais resultados com aplicação de quizzes os quais contendo as mesmas questões o nível de acerto manteve muito próximo do quantitativo médio percentual. 
O Quadro 2 exibe os totais de alunos já considerando as duas turmas que acabaram cedendo a tentação de "cola" e o quantitativo dos alunos rotulados independentes. Dos 160 alunos, 17 obtiveram a nota máxima de sete. Cerca de 13 alunos variaram entre 6,0 e 6,9. Perfazendo um percentual de $8,3 \%$ (16 discentes), se enquadraram no intervalo de 5,1 e 5,9. Os demais, $71,3 \%$ falharam com a prática da cola na aprendizagem.

Quadro 2-Quantitativo de alunos que praticaram e não praticaram cola

\begin{tabular}{|c|c|c|}
\hline Semestres & $\begin{array}{c}\text { Alunos } \\
\text { independentes }\end{array}$ & $\begin{array}{c}\text { Alunos que } \\
\text { praticaram } \\
\text { a "cola" }\end{array}$ \\
\hline 2012.1 & 3 & 20 \\
\hline 2012.2 & 2 & 14 \\
\hline 2013.1 & 2 & 38 \\
\hline 2013.2 & 5 & 32 \\
\hline 2014.1 & 5 & 56 \\
\hline Total & $\mathbf{1 7}$ & $\mathbf{1 6 0}$ \\
\hline
\end{tabular}

Fonte: Pesquisa de campo

Embora o percentual de falha se delineia significativo, os resultados demonstram uma "janela" para se obter uma aprendizagem condizente com o esforço que não se firmou tão assim diminuto. Foi observado que as falas foram ponderadas, material bibliográfico selecionado e sintetizado, discussões reduzidas ao momento exigido e a decisão da escrita definitiva tomada.

\section{Considerações finais}

É evidente que um único momento não é suficiente para verificar se, realmente, está consolidada a aprendizagem. Por isso, é importante o professor realizar registros durante o processo, aplicar instrumentos avaliativos e, no caso específico da avaliação dos procedimentos, observar o aluno em diferentes situações, desenvolvendo as ações específicas que evidenciam o saber fazer. A realidade empírica comprova claramente essa lógica teórica, particularmente a visão delineada por Melchior (2003).

Não obstante, é impossível negar que a "cola" não seja um recurso de aprendizagem. A pesquisa confirmou que do total de 160 sujeitos de pesquisa, 46 obtiveram êxito em sua aprendizagem. 28,7\% dos estudantes em Análise de Investimentos conseguiram estabelecer relações com outros conceitos discutidos na disciplina, fazer interpretação de variáveis conceituais contextualizadas em mini casos e principalmente se posicionar criticamente diante de provocações no teor de questões, mesmo de posse de objetos bibliográficos e sussurros entre os colegas.

Boa parte dos $71,3 \%$ dos alunos que obtiveram insucesso demonstrou imensas dificuldades de sequer extrair uma leitura analítica de representações gráficas.

Apesar de todo o cuidado que procurou imprimir na pesquisa é claro que deve conter vieses. Estes nunca ficam isentos. Usualmente percebe-se que o aluno só manifesta um desempenho favorável de sua aprendizagem quando se está sob pressão. E esse fato deve ter exercido alguma interveniência na decisão de colar. A própria elaboração da prova pode ter ficado em desacordo com o que pensam os especialistas no tocante ao seu formato. Por isso um pouco de ceticismo e cautela deve ser dado a este estudo, afinal como instrui Khan (2013), a precisão e significância dos resultados de testes, provas e exames nunca devem ser considerados uma garantia.

Como recomendação de estudos futuros a replicação da pesquisa em outras disciplinas se extrairia uma comparação mais consistente. Inclusive qual seria o desempenho da 
aprendizagem em um processo de cola assistida se em um mesmo espaço contivesse alunos de cursos e disciplinas distintas?

\section{Referências Bibliográficas}

ANDRÉ, M. E. D. A. de. Estudo de caso em pesquisa e avaliação educacional. Brasília: Liber, 2005.

BARBOSA, E. B. "Cola" em sala de aula: a taxionomia é o antídoto. Cuadernos de Educación y Desarollo, v. 7, 2013.

COOPER, D. R. e SCHINDLER, P. S. Métodos de pesquisa em administração. 7 ed. Porto Alegre: Bookman, 2003

CRUZ NETO, O. O trabalho de campo como descoberta e criação. In: MINAYO, M. C.de S. (Org.). Pesquisa social: teoria, método e criatividade. 19 ed., Petrópolis, RJ: Vozes, 1994.

ELIA, L. O conceito de sujeito. 3 ed. Rio de Janeiro:Zahar, 2010.

GIL, A. C. Didática no ensino superior. São Paulo: Atlas, 2006.

LOWMAN, J. Dominando as técnicas de ensino. São Paulo: Atlas, 2004.

KHAN, S. Um mundo sem escola: a educação reinventada. Rio de Janeiro: Intrínseca, 2013.

MELCHIOR, M. C. Da avaliação dos saberes à construção de competências. Porto Alegre: Premier, 2003.

MORETTO, V. P. Prova: um momento privilegiado de estudo, não um acerto de contas. 8 ed., Rio de Janeiro: Lamparina, 2008.

MOURA, M. L. S. de, FERREIRA, M. C. e PAINE, P. A. Manual de elaboração de projetos de pesquisa. UERJ: Rio de Janeiro, 1998.

PIMENTA, M. A. A. Fraude em avaliações na visão de professores e de estudantes: uma reflexão sobre a formação profissional e ética. Revista Profissão Docente. v. 10, n. 22, jul/dez.2010.

RIBEIRO, R. O aluno colou? É hora de discutir avaliação. E regras. Nova Escola, jul.2004.

SAMAJA, J. Epistemología y metodologia: elementos para uma teoria de La investigación científica. 3 ed. Bueno Aires: Editorial Universitária de Bueno Aires, 2002.

SANTOS, A. L. dos. Reflexões sobre a cola. Disponível em http://www.hottopos.com/regeq9/andre.htm. Acessado em 01.05.14.

STENHOUSE, R. Case study methods. In KEEVES, J. P.(ed.), Educational Research, Methodology, and measurement: an international Handbook, Osford: Pergamon, 1988.

WOOD Jr., T. A crise do giz. Carta Capital, 15.12.2013. 